\title{
Early Intermittent Self-catheterisation after Spinal Cord Injury
}

\author{
J. J. Wyndaele, $M D,{ }^{1}$ N. De Taeye $\mathbf{R N}^{2}$ \\ ${ }^{1}$ Centre for Urodynamics and Urological Rehabilitation, ${ }^{2}$ Centre for Rehabilitation, \\ University Hospital, State University, Ghent, Belgium.
}

\begin{abstract}
Summary
An evaluation has been made of intermittent self-catheterisation (ISC) carried out by 25 paraplegic patients early after injury. The results were compared with those of intermittent catheterisation (IC) done in another 48 paraplegic patients by a catheter team. No significant difference was found regarding the rate of urinary infection or the incidence of urethral trauma. The final outcome of bladder training did not differ significantly between the two groups. Patients on self-catheterisation went home earlier for the weekend. Most patients and their relatives found that self-catheterisation in the early stage was easy to perform and meant a more active participation in bladder training. Early self-catheterisation may help to overcome a nursing staff shortage in a busy acute spinal cord injury ward.
\end{abstract}

Key words: Paraplegia; Neuropathic bladder; Catheterisation.

Intermittent catheterisation has proved to be a very valuable method of bladder drainage in the early post-injury period (Bors, 1967; Guttmann and Frankel, 1966; Ott and Rossier, 1972; Wyndaele et al., 1985) as well as in the chronic stage after spinal cord injury (SCI) (Firlit et al., 1975).

The use of a non-touch technique done by nurses, technicians or aides may be time-consuming. In a busy SCI ward supplementary nursing staff might be needed (Madersbacher, 1973; O'Flynn, 1974). Although some studies mention catheterisation by patients themselves (Comarr, 1972; Sperling, 1978; Stover et al., 1973) most of these deal with chronic patients who were treated previously with an indwelling catheter for several weeks or months.

In this study we state the results of ISC done in the acute stage, and compare them with those of a group of spinal injury patients catheterised by a catheter team.

Correspondence to: Dr J. J. Wyndaele, CUUR, Department Urology, UZ, 185 De Pintelaan, B-9000 Ghent, BELGIUM. 


\section{Patients and methods}

Starting from 1 December 1986 self-catheterisation was learned by paraplegic patients as soon as they arrived at the spinal unit and under the following conditions: they had no previous history of urethral trauma or of catheterisation difficulties; their general medical condition was good; and they could be in a sitting position. The first 25 patients using this method are included in this study. Most of them $(80 \%)$ had a traumatic spinal cord injury. There were 22 males and 3 females, with a mean age of 34 years (range 16-59 years). Fourteen had a spinal lesion above D7, 6 between D8 and D11 and 5 below D12. Their social status was very divergent: 14 had a college degree, 9 were labourers and 2 were housewives.

The interval between the SCI and the time that self-catheterisation was started

Table I Time of commencing intermittent self-catheterisation

\begin{tabular}{cc}
\hline Days & No of patients \\
\hline $0-7$ & 1 \\
$8-28$ & 6 \\
$29-56$ & 10 \\
$57-84$ & 5 \\
$85+$ & 3 \\
\hline
\end{tabular}

varied between 1 and 40 weeks (mean 5 weeks, Table I). Most patients had been treated before with intermittent catheterisation by a catheter team. All patients were still in spinal shock or in the very early period of bladder training.

Male patients used a disposable curved-tip catheter Charrière 14, and they used a clean technique washing their hands and the meatus, disinfecting the meatus with Chloramine 3\%o aqueous solution, and carbol oil $2 \%$ as a lubricant. The catheter was mainly handled with forceps.

It took a mean of 3 catheterisations (between 1 and 12) under close surveillance by a staff nurse before patients became independent in this aspect.

Female patients used disposable female catheters Charrière 14 and a clean nonsterile technique: after washing their hands and the meatus, disinfection with Chloramine 3\%o aqueous solution, and no lubricant was used. Most female patients used a mirror which was fixed in front of them. A mean of 4 catheterisations (112) were necessary for female patients to become independent in catheterising themselves.

Urine was examined twice a week, and all related complications were notified. Evaluation was made concerning the number of patients becoming catheter-free, the incidence of urethral trauma, and the incidence of urinary tract infection.

The results were compared with those of 48 paraplegic patients of comparable age, sex and level of spinal cord lesion, treated before 1 December 1986 with IC done by a catheter team during their entire bladder rehabilitation period. A nontouch technique was used in this group. The statistical analysis was made with the Chi-square test.

Patients in the self-catheterisation group answered a questionnaire concerning 
the method 1 month after they started to catheterise themselves. The results of this evaluation will be discussed.

\section{Results}

Seventy-two per cent of the self-catheterisation group (18 patients) achieved a state of balanced bladder ${ }^{\star}$ after a mean period of 5 weeks. This result is very comparable

Table II Comparison between results in the self-catheterisation group and the group catheterised by the catheter team

\begin{tabular}{|c|c|c|c|c|c|c|c|c|}
\hline & \multirow{2}{*}{$\begin{array}{c}\text { Total } \\
\text { number } \\
\text { of patients }\end{array}$} & \multicolumn{3}{|c|}{$\begin{array}{c}\text { Bladder drainage at } \\
\text { discharge }\end{array}$} & \multirow{2}{*}{$\begin{array}{l}\text { Urethral } \\
\text { trauma }\end{array}$} & \multicolumn{3}{|c|}{ UTI at discharge } \\
\hline & & Catheter-free & IC & $\mathrm{FC}$ & & $\begin{array}{c}\text { Data } \\
\text { incomplete }\end{array}$ & $\begin{array}{l}\text { Urine } \\
\text { sterile }\end{array}$ & $\begin{array}{l}\text { Urine } \\
\text { infected }\end{array}$ \\
\hline Catheter team & 48 & $38(79 \%)$ & 7 & 3 & 2 & 2 & $28(+5)$ & 13 \\
\hline Self-catheterisation & 25 & $\begin{array}{c}18(72 \%) \\
\text { NS }\end{array}$ & 7 & - & $\begin{array}{c}0 \\
\text { NS }\end{array}$ & 3 & $\begin{array}{c}15(+1) \\
\text { NS }\end{array}$ & 6 \\
\hline
\end{tabular}

IC: continue on self-catheterisation

FC: continue on indwelling Foley catheter

UTI rate at discharge: number of patients in parentheses = number under antibacterial treatment

NS: statistically: no significant difference (Chi-square test)

with that found in the other group (Table II). There was no significant difference in the incidence of urethral trauma (Table II).

\section{Urinary tract infection (UTI)}

To evaluation the incidence of UTI proved very difficult: infection was present in some patients when they entered the study, some patients remained chronically infected, antibiotics for an unrelated cause had to be given in several patients during the evaluation period, a number of doubtful laboratory results were seen.

No cross infection was noticed between patients in the self-catheterisation group. In two instances, cross infection appeared amongst several patients in the other group.

The UTI rate at discharge is given in Table II. In both groups patients could be kept sterile for long periods with a prophylaxis of low dose Nitrofurantoin MC (100 mg once or twice daily).

In all patients of both groups at least 1 period of UTI was noticed. The data are too incomplete however to make a comparison between the groups possible.

Patients on self-catheterisation could go home for a 1 or 2 day weekend as early as 3 weeks after admission to the spinal unit. This was a much shorter period than before self-catheterisation was started (mean of 7 weeks); the fact of being

\footnotetext{
* The term 'balanced bladder' describes a state where patients can empty their bladder by tapping and/or crédé and/or straining at a \pm 4 hour interval ( 8 hours at night) with a maximum intravesical pressure below $60 \mathrm{~cm} \mathrm{H} \mathrm{H}_{2} \mathrm{O}$ and with an acceptable continence in between (i.e. occasionally wet), while their residue is as low as necessary to permit all this (mainly less than $50 \mathrm{ml}$, in some up to $100 \mathrm{ml}$ ). Regular catheterisations are no longer done in these patients.
} 
independent for bladder drainage seemed to play a major role in this. The answers to the questionnaire are given in Table III.

Table III Answers given by 25 patients to questionnaire 1 month after they started self-catheterisation

\begin{tabular}{lrr}
\hline Questions & \multicolumn{2}{c}{ Answers } \\
& Yes & No \\
\hline Self-catheterisation is & & \\
- mostly to relieve the nurses & $22 \%$ & $78 \%$ \\
- difficult & $16 \%$ & $84 \%$ \\
- an active participation in the bladder training & $74 \%$ & $26 \%$ \\
- time consuming & $10 \%$ & $90 \%$ \\
- easy during weekend & $94 \%$ & $6 \%$ \\
- a definitive solution to bladder problems & $35 \%$ & $65 \%$ \\
Are you afraid to traumatise yourself with the catheter? & $39 \%$ & $61 \%$ \\
Does your family have a positive reaction? & $90 \%$ & $10 \%$ \\
\hline
\end{tabular}

\section{Discussion}

The results of this study prove that early self-catheterisation by many paraplegic patients is both practical and safe. The incidence of urethral trauma and the infection rate did not differ significantly from those patients catheterised by a catheter team.

The introduction of a catheter team can significantly refuce the UTI rate in a spinal unit (Lindan, 1969; Pearman, 1977). This was also our experience, although cross-infection still occurred (De Taeye et al., 1985). The results presented here demonstrate that early self-catheterisation by paraplegic patients gave good results, comparable with those of a catheter team, but ISC made cross infection completely disappear.

The fear that more patients would continue on IC after discharge if they learned early to catheterise themselves proved unrealistic: the percentage of catheter-free patients in both groups was practically equal.

The evaluation by the patients themselves, as is shown in the questionnaire, can be considered quite positive: patients felt more personally involved in bladder management; most did not find self-catheterisation difficult. The majority however did not consider self-catheterisation a definite solution to their bladder problems.

Although most patients did not feel that the method was mainly meant to relieve the nursing staff, self-catheterisation proved to reduce to a certain extent the work load of the nursing staff.

Only those patients able to catheterise themselves are suitable candidates. In our experience, the method is to be used during the early period only by those paraplegic patients who are able to sit up, are in good general condition, and have not had any previous catheterisation problems.

\section{References}

BoRS E 1967 Intermittent catheterization in paraplegic patients. Urologia Internationalis 22:236-249. COMARR AE 1972 Intermittent catheterization for traumatic cord bladder patient. Fournal of Urology 108:79-81. 
Firlit CS, CANning JR, Lloyd FA, Cross RR, Brewer R Jr 1975 Experience with intermittent catheterization in chronic spinal cord injury patients. Fournal of Urology 114:234-236.

GUTTMANN L, FRANKEL H 1966 The value of intermittent catheterization in the early management of traumatic paraplegia and tetraplegia. Paraplegia 4:63-84.

LINDAN R 1969 The prevention of ascending catheter-induced infections of the urinary tract. Fournal of Chronic Diseases 22:321-332.

MADERSBACHER H 1973 Probleme bei des Harnableitung frischer Quer-schnittspatienten. MschrUnfallheilk 76:461-466.

O'FLYNN JD 1974 Early management of neuropathic bladder in spinal cord injuries. Paraplegia 12:83-86.

OTt R, Rossier AB 1972 L'Intérêt du sondage intermittent dans la rééducation vesicale des lesions médullaires traumatiques aiguës. Urologia Internationalist 27:51-65.

PEARMAN JW 1977 The catheter team: an essential service for rehabilitating neurogenic bladders. Australian and New Zealand Fournal of Surgery 47:339-343.

SPERLING KB 1978 Intermittent catheterization to obtain catheter free bladder function in spinal cord injury. Archives of Physical Medicine and Rehabilitation 59:4-8.

Stover SL, Miller JM III, NePOMUCENo CS 1973 Intermittent catheterization in patients previously on indwelling catheter drainage. Archives Physical Medicine and Rehabitation 54:25-30.

Wyndaele JJ, De Sy WA, Claessens H 1985 Evaluation of different methods of bladder drainage used in the early care of spinal cord injury patients. Paraplegia 23:18-26. 